\title{
Erratum to: Role of plant growth promoting rhizobacteria in the remediation of metal contaminated soils
}

\author{
Mohammad Saghir Khan • Almas Zaidi • \\ Parvaze Ahmad Wani · Mohammad Oves
}

Published online: 9 December 2011

(C) Springer-Verlag 2011

\section{Erratum to: Environ Chem Lett (2009) 7:1-19 \\ DOI 10.1007/s10311-008-0155-0}

The authors unintentionally omitted to mention the correct references to Figs. 8 and 10.

The reference to Fig. 8 should have read as follows:

Greger M (1999) Metal availability and bioconcentration in plants, pp. 1-27. In: Prasad MNV and Hagemeyer J (eds) (1999) Heavy metal stress in plants: from molecules to ecosystems. Springer-Verlag, Heidelberg, $401 \mathrm{pp}$ and Prasad MNV, Greger M, Smith BN (2001) Aquatic macrophytes, pp. 259-288. In: Prasad MNV (ed) Metals in the environment: analysis by biodiversity. Marcel Dekker Inc., New York, 504 pp.

The reference to Fig. 10 should have read as follows:

Adapted from "Devi SR, Prasad MNV (1999) Membrane lipid alterations in heavy metal exposed plants. In: Prasad MNV, Hagemeyer J (eds) Heavy metal stress in plants: from molecules to ecosystems, Springer-Verlag, Berlin, Heidelberg, New York, pp. 99-116.” Adapted with permission.

The authors sincerely regret the omission and apologize for any inconvenience caused.
The online version of the original article can be found under doi: 10.1007/s10311-008-0155-0.

M. S. Khan $(\bowtie) \cdot$ A. Zaidi · P. A. Wani · M. Oves Department of Agricultural Microbiology, Faculty of Agricultural Sciences, Aligarh Muslim University, Aligarh 202002, India

e-mail: khanms17@rediffmail.com

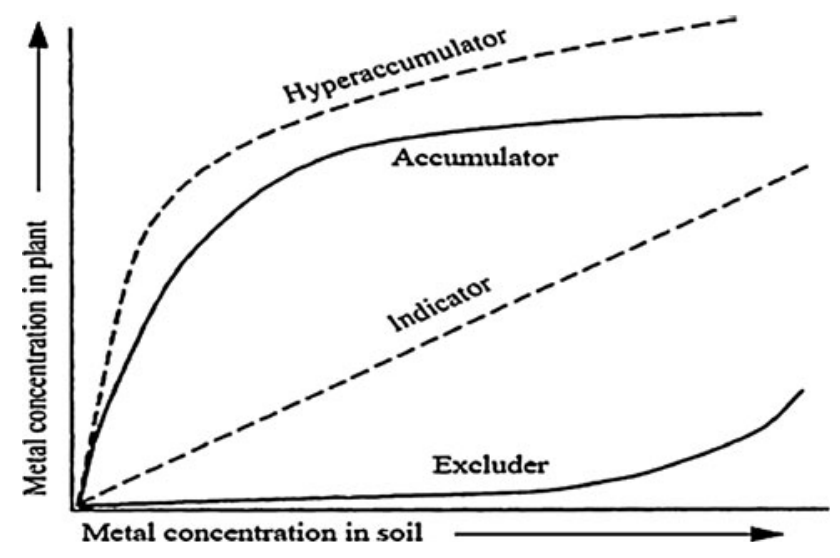

Fig. 8 Strategies of metal uptake by plants depending on the concentration of metal in soil (adapted from Adriano 2001) 
Fig. 10 Metabolism of plants damaged by heavy metals

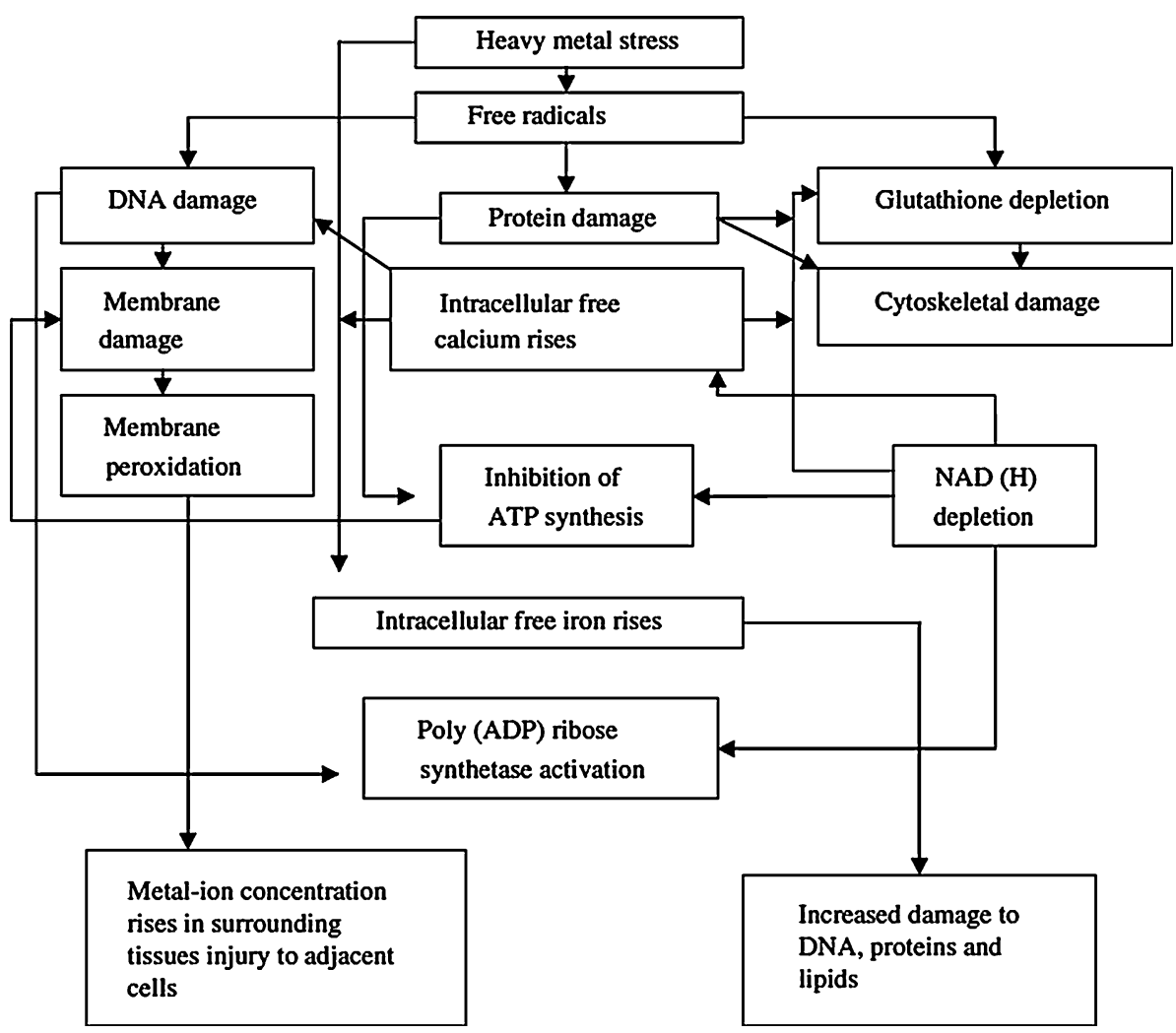

